\title{
Dimensões religiosas da radicalização política no Brasil contemporâneo
}

\section{Religious dimensions of the political radicalization in contemporary Brazil}

\section{Brenda Carranza ${ }^{a} \odot$, Renan William dos Santos ${ }^{b} \oplus$, Luiz Jácomo ${ }^{c}($}

Resumo Neste texto são apresentadas reflexões acerca das complexas relações entre religião e política no Brasil, especificamente na última década. A radicalização política tem sido a tônica da governabilidade institucional e da participação popular nas relações de poder, e nesse ínterim a dimensão religiosa tem se tornado cada vez mais saliente. Grupos religiosos estreitam relações entre conservadorismo político e cristianismo, deflagrando uma politização reativa que não se limita a acionar as moralidades religiosas como fiadoras da gestão da res publica, mas também recorrem a um amplo instrumental secular, composto de mecanismos jurídicos e legislativos. Após apresentação sobre a materialização desses fatores no cenário nacional contemporâneo, segue-se uma apreciação das análises e pesquisas que compõem o presente dossiê, o qual procura problematizar, à luz de interpretações sociológicas, a interação entre religião e política e suas consequências na realidade social brasileira.

Palavras-chave Religião. Política. Radicalização. Conservadorismo. Brasil.

Abstract This text presents reflections on the complex relations between religion and politics in Brazil, specifically in the last decade. Political radicalization has been the gist of institutional governance and popular participation in power relations, and in the meantime the religious dimension has become increasingly prominent. Religious groups have strengthened relations between political conservatism and Christianity, triggering a reactive politicization that is not limited to using religious moralities as guarantors for the management of the res publica, since they also make use of a

a Professora e pesquisadora colaboradora do Departamento de Antropologia Social da Universidade Estadual de Campinas (Unicamp), Brasil. Pesquisadora Associada ao Programa Condiciones de vida y Religión, do Instituto de investigaciones en la Facultad de Ciencias Sociales de la Universidad Católica de Argentina. Coordenadora do Laboratório de Antropologia da Religião - LAR/Unicamp. Vice-líder do Gênero, Religião e Política -GREPO/PUC-SP. E-mail: brenda_poveda@terra.com.br

b Doutorando no Programa de Pós-Graduação em Sociologia da Universidade de São Paulo (PPGS-USP), Brasil, com apoio da Fundação de Amparo à Pesquisa do Estado de São Paulo (FAPESP), processo 2017/24842-1. E-mail: renan16@outlook.com

c Doutorando no Programa de Pós-Graduação em Sociologia da Universidade de São Paulo (PPGS-USP), Brasil. Membro do grupo de pesquisa "Diversidade religiosa na sociedade secularizada" (CNPq). O presente trabalho foi realizado com apoio da Coordenação de Aperfeiçoamento de Pessoal de Nível Superior - Brasil (CAPES) - Código de Financiamento 001. E-mail: luizvjj@gmail.com 
wide range of secular instruments, composed of legal and legislative mechanisms. After a presentation on how these factors take place in the contemporary national scenario, the text follows with an assessment of the works that make up this thematic dossier, which seek to problematize, in the light of sociological interpretations, the interaction between religion and politics and its effects on Brazilian social reality.

Keywords Religion. Politics. Radicalization. Conservatism. Brazil.

\section{RADICALIZAÇÃO EM CURSO}

Ventos fortes vêm chacoalhando o cenário político brasileiro, especialmente na última década. Desde as manifestações de 2013, quando milhões de brasileiros foram às ruas, muitos manifestando suas opiniões políticas de forma direta pela primeira vez, o que se assistiu em seguida foi uma série de acontecimentos que esgarçaram os limites institucionais democráticos e republicanos (Alonso, 2017). O impeachment da então presidenta Dilma Rousseff em 2016, seguido pelo extensivo uso da lawfare durante as eleições presidenciais de 2018 (GABARDo et al, 2021), erigiram uma figura obscura do baixo clero da Câmara dos Deputados ao cargo maior do executivo nacional. Em meio a essa turbulência da vida pública brasileira, nunca se falou tanto de política - e, ao mesmo tempo, nunca se falou tanto em religião e política.

Em grande parte, tal cenário decorreu da extensiva instrumentalização do simbolismo religioso na corrida presidencial. Ainda em maio de 2016, dois meses após o lançamento de sua pré-candidatura à presidência pelo Partido Social Cristão (PSC), Jair Bolsonaro, assumidamente católico ${ }^{1}$, foi batizado nas águas do Rio Jordão, em Israel, pelo então presidente de seu partido, Pastor Everaldo - que acabaria preso em 2020, em plena pandemia, por envolvimento em desvios de verba pública. Os acenos aos segmentos cristãos conservadores (sobretudo evangélicos), contudo, já vinham de longa data.

Curiosamente, um dos marcos iniciais dessa aproximação foi a performance de Bolsonaro na Comissão de Direitos Humanos e Minorias (CDHM) em 2011, durante a famigerada controvérsia sobre os materiais didáticos (apelidados de "kit gay”) distribuídos pelo Ministério da Educação, à época comandado por ninguém menos que Fernando Haddad, adversário de Bolsonaro no segundo turno das eleições presidenciais de 2018. Foi a partir dessa controvérsia que a CDHM ganhou protagonismo na agenda da cristã conservadora, o que culminou na eleição de

1 A postura extremamente "flexível" de Bolsonaro na composição simbólica de sua identidade religiosa é reproduzida em diversas outras esferas, indo da visão sobre qual deve ser o papel do Estado na economia até a escolha de times de futebol. 
Marco Feliciano para a presidência da Comissão em 2013, um dos marcos da demonstração de poder político das lideranças evangélicas à época.

No ano seguinte, 2014, foi a vez do próprio Bolsonaro concorrer à presidência da CDHM, com apoio de Feliciano. Devido a importância simbólica que a comissão ganhou, no entanto, o governo então comandado pelo PT de Dilma Rousseff investiu força máxima no pleito e conseguiu articular a eleição (apertada, com diferença de apenas dois votos) do deputado petista Assis do Couto, escolhido justamente por seu perfil mais "palatável" junto aos setores religiosos conservadores - católico, Couto integrava no Congresso a "Frente Mista em Defesa da Vida Contra o Aborto".

De volta à corrida presidencial de 2018, por mais que o alinhamento entre Bolsonaro e diversas lideranças religiosas fosse proclamado por ambas as partes, sobretudo para a público de fiéis, como uma questão de valores, as articulações propostas (e efetivadas após a eleição) não diferiram muito da fórmula adotada nos governos anteriores ${ }^{2}$. Elas consistem, basicamente, na troca de suporte financeiro e midiático por favores e privilégios políticos, tais como nomeações em cargos públicos, direcionamento de verbas estatais, isenção de impostos, perdão de dívidas dos templos etc. (Prandi; Santos; Bonato, 2019).

E mesmo se levarmos em conta a exibição pública dessas articulações, também não é novidade a presença de presidenciáveis nos bancos das igrejas, isso quando não falam diretamente de seus púlpitos, com as bênçãos dos mais variados pastores, apóstolos e bispos. A capacidade de orientação política dessas lideranças religiosas, entretanto, geralmente é exagerada - tanto por algumas análises mais desatentas, quanto pelos próprios líderes que querem aumentar o valor do seu "produto" na barganha política (PrANDI; SANTOS, 2017). A esse respeito, basta lembrar que, quase invariavelmente, tais líderes religiosos costumam abençoar aqueles que estão à frente das pesquisas de intenção de votos. É assim que, para ficar em apenas um exemplo, Edir Macedo, após ter sido um crítico ferrenho de Lula3 ${ }^{3}$ virou um aliado histórico do Partido dos Trabalhadores ${ }^{4}$ - o que não o impediu de, em 2018, declarar seu apoio ao projeto bolsonarista às vésperas do segundo turno.

2 Fórmula esta já empregada desde os tempos da Assembleia Constituinte de 1987-88 (Pierucci, 1996).

3 Ver https://jornal.usp.br/artigos/sem-protagonismo-a-bancada-evangelica-danca-conforme-a-musica-no-congresso-nacional/. Acesso em o6 de junho de 2021.

4 Sobre essa aliança, vale lembrar que o vice de Lula durante seus dois mandatos, José de Alencar, era presidente de honra do PRB (atual Republicanos), um reconhecido braço político da Igreja Universal. 


\section{POLITIZAÇÃO REATIVA DOS GRUPOS RELIGIOSOS}

As declarações públicas dos que estão envolvidos no jogo político, portanto, nem sempre correspondem de forma clara às estratégias que estão sendo postas em prática nas diversas instâncias de poder. É justamente com essa questão que o dossiê aqui apresentado procura contribuir. Nele, buscamos reunir análises sobre como os diferentes temas em debate na esfera pública brasileira têm sido concretamente articulados por agentes religiosos em sua atuação política.

O cenário resultante, como os leitores e leitoras poderão constatar, é muito mais complexo do que poderia parecer à primeira vista. Em alguns casos, há uma reação que busca barrar o avanço de transformações sociais mais amplas, como a secularização ou a liberalização dos costumes. Em outros, trata-se de propor uma maior abertura aos novos costumes, práticas e concepções. Ainda, os mesmos atores, instituições e denominações religiosas podem se posicionar de uma maneira que consideram "progressista" em certo tema, e de maneira "conservadora" em outro. Mas não é só a autoconcepção dos grupos que conta. "Progressismo" e "conservadorismo" são categorias relacionais que variam conforme o tempo e dependem das disputas em jogo tanto no próprio campo religioso quanto no contexto social mais amplo - que ultrapassa o limite das disputas políticas. É inegável, porém que, dentre tais disputas, aquelas que têm ocorrido na esfera política são as que têm recebido mais atenção, sobretudo em razão da "onda conservadora" que vem se formando no país nos últimos anos. Essa onda, porém, é "quebrada”, ou seja, não é uniforme, possuindo relação com processos sociais "desiguais, assimétricos e com temporalidades distintas” (ALMEIDA, 2017, 2019, p. 210).

No plano eleitoral das corridas presidenciais, uma dessas "quebras" é extremamente significativa: diferentemente do que ocorreu com José Serra na corrida presidencial de 2010, o reiterado uso de argumentos e apelos religiosos por Bolsonaro não saturou as sensibilidades ao ponto de chegar a ser considerado "abusivo" ou "descabido" sobretudo pelo eleitorado cristão conservador. O "efeito fariseu" do qual falava Pierucci (2011, p. 11), ou, em outras palavras, a repulsa a figuras políticas que passam a ser vistas como religiosamente hipócritas, posto que ostentam sua fé apenas de forma ritual/formal (a "santidade exterior"), não afetou Bolsonaro - mesmo sendo públicas diversas características de sua trajetória pessoal que possibilitariam o surgimento desse fenômeno.

Em primeiro lugar, Bolsonaro nunca foi um exímio cumpridor de vários ideais comportamentais valorizados pelo cristianismo tradicionalista. Para dar apenas alguns exemplos, Bolsonaro já estava em seu terceiro casamento (nem todos 
eles oficializados) ${ }^{5}$, reconheceu um dos filhos apenas após exame de $\mathrm{DNA}^{6}$, teve términos de relacionamento conturbados ${ }^{7}$, exibe verborragia obscena ${ }^{8}$, declarou em canal aberto da TV já ter praticado zoofilia ${ }^{9}$, e chegou a conceder entrevista dizendo que deixou a decisão de abortar um de seus filhos nas mãos de sua mulher ${ }^{10}$. Já fora da vida pessoal, isto é, na arena pública, fazia (e segue fazendo) inúmeras declarações em favor da criminalização do aborto, protestos pelo resgate da moralidade deturpada ao longo dos últimos anos, afirmações sobre a família tradicional como a base da vida social e da manutenção da pátria, reivindicações de ensinamentos bíblicos como régua moral etc.

Dado esse cenário, são grandes as chances de que o tal efeito fariseu não tenha ocorrido em razão do fato de Bolsonaro ter tido sua campanha pública precocemente interrompida ao ser esfaqueado, o que o poupou dos debates e sabatinas característicos das retas finais da campanha. A blindagem foi decisiva sobretudo no segundo turno, quando o escrutínio é maior e, como aconteceu com Serra, tendem a se tornar de conhecimento geral as contradições entre a persona publica, que se declara campeã da moral, e a persona privada, com seus comportamentos demasiado humanos. Assim, ao sobreviver ao atentado, Bolsonaro vestiu o manto de mártir, encarnando o personagem responsável por ter dado o sangue pelo país.

Esse contexto político dominado pela retórica conservadora resultou em uma composição ainda mais favorável para a politização reativa dos setores religiosos (VAGGIONE, 2020). Lideranças católicas e evangélicas expandiram, assim, sua união no Congresso Nacional, por meio do bloco cristão, para atuar na contraposição de propostas relativas à expansão de direitos reprodutivos e LGBTQI+, bem como na defesa de extravagâncias legislativas como o projeto Escola sem Partido - projeto que, no limite, permitia o ensino do criacionismo e a defesa da primazia das características biológicas nas relações de gênero em escolas públicas e particulares do Brasil.

5 Ver https://brasil.elpais.com/brasil/2020-08-29/as-mulheres-do-cla-bolsonaro.html. Acesso em 06 de junho de 2021.

6 Ver https://www.bol.uol.com.br/noticias/2021/05/10/ana-cristina-valle-bolsonaro-miss-rachadinha.htm. Acesso em 06 de junho de 2021.

7 Ver https://oglobo.globo.com/epoca/brasil/como-os-casamentos-de-bolsonaro-estao-conectados-com-as-investigacoes-sobre-seus-filhos-24581796. Acesso em o4 de junho de 2021.

8 Ver https://www1.folha.uol.com.br/poder/2020/o5/reuniao-ministerial-sob-investigacao-teve-ao-menos-37-palavroes-bolsonaro-lidera-com-29-confira-a-lista.shtml. Acesso em 04 de junho de 2021.

9 Ver https://youtu.be/aSJsXlkVtq8?t=354. Acesso em 04 de junho de 2021.

10 Ver https://www1.folha.uol.com.br/poder/2018/o8/homem-nao-deve-intervir-na-decisao-da-mulher-sobre-aborto-diz-bolsonaro.shtml. Acesso em 30 de maio de 2021. 
Ainda que representantes de identidade católica integrem tal aliança, no entanto, a Igreja Católica no Brasil vem enfrentando agudos embates internos entre setores reacionários e progressistas, conflitos esses evidenciados em eventos como a Campanha da Fraternidade de 2021 (CF-2021) e o Sínodo da Amazônia. Atingida em cheio pelo clima de radicalização, a instituição católica viu-se acusada por setores conservadores de fomentar, através da CF-2021, "uma infiltração da 'extrema esquerda revolucionária' [...] com o objetivo de defender a ideologia de gênero, as minorias, denunciar o feminicídio e o racismo" (Teixeira; Carranza, 2021). Isso tudo simplesmente porque o manual da campanha atentava para as diferentes violências que se manifestavam de modo geral na sociedade brasileira, em especial àquelas vivenciadas pelas mulheres, negras e indígenas, e pela população LGBTQI+.

Já em 2020, no Sínodo da Amazônia, evento convocado para discutir os rumos da Igreja Católica nos países que compartilham entre si territórios da floresta, a controvérsia gerada foi ainda mais virulenta, mobilizando sacerdotes, influenciadores digitais, políticos e grupos religiosos para denunciar o que seria visto como a deturpação ao mesmo tempo da fé católica e da soberania nacional ${ }^{11}$ (SANTos, 2020). No Brasil, a ponta de lança dessa reação foi o Instituto Plínio Correa de Oliveira (IPCO), um think tank católico conservador que tem no seu rol de atuações a oposição à pauta ecológica, descrita pelo grupo como "psicose ambientalista" expressão que, não à toa, foi adotada por Bolsonaro e seus seguidores em diversas ocasiões em que a pauta ambiental estava em discussão (SANTos, 2020).

Vê-se, portanto, que em sua atuação pública, os grupos religiosos, principalmente aqueles situados a direita do espectro político, tendem a assumir a forma de "contramovimentos de resistência à mudança" (Silva; Pereira, 2020). Ainda, percebe-se que esses mesmos grupos estão cada vez mais hábeis em acionar a conjugação entre o sistema político e suas crenças religiosas. Seus líderes e representantes políticos têm logrado êxito em atuar nos limites do republicanismo e da democracia, mobilizando o argumento da laicidade do Estado em duas chaves distintas, mas sempre a seu favor: ora demandando a liberdade de religião sem constrangimento, ora demandando a defesa de interesses (e valores) próprios pelo aparato estatal. E nessa trilha interpretativa de discursos como geradores

11 Em uma reunião fechada do poder executivo nacional sobre planos de ocupação da Amazônia, o evento promovido pela Igreja Católica foi descrito da seguinte maneira: "O Sínodo da Amazônia vai trazer problemas seríssimos para nós, porque ele vem com viés ambientalista, contra tudo o que a gente pensa” Disponível em <https://theintercept.com/2019/o9/19/plano-bolsonaro-paranoia-amazonia/>. Acesso em 20 de abril de 2021. 
de ações, e de ações como geradores de discursos (Foucault, 2019), os textos que apresentamos neste dossiê nos permitem acessar um recorte sobre a realidade por meio de variadas temáticas, metodologias e abordagens analíticas do atual cenário religioso brasileiro. Vejamos.

\section{RECORTES ANALÍTICOS: SEGUINDO A TRILHA DE PERTINENTES QUESTIONAMENTOS}

Maria José Rosado Nunes, Olívia Bandeira e Gisele Cristina Pereira, no artigo "A quem pertence o termo "católicas”? Direito e mídia como arenas e estratégias do neoconservadorismo", analisam as disputas recentes envolvendo a ONG Católicas pelo Direito de Decidir e o Centro Dom Bosco, grupo ultraconservador que requereu na justiça a proibição do uso do definidor "católicas" pela ONG, o que foi acatado. Ao examinarem as questões envolvidas nessa disputa, as autoras combinam a análise do arsenal documental judiciário com o levantamento de enunciados e notícias veiculadas nas mídias sociais religiosas, desvendando a relação entre processo judiciário e a apropriação que as mídias religiosas (tradicional, internet, redes sociais) fazem dele. Para as autoras, a performatividade judiciária adotada pelos grupos ultraconservadores, que reivindicam o uso do adjetivo identitário "católico", constitui um movimento público de recuperação de uma hegemonia valorativa intimidada pelos avanços do feminismo e grupos LGBTQI+.

Já Christina Vital da Cunha, em "Cultura pentecostal em periferias cariocas: grafites e agenciamentos políticos nacionais", analisa as expressões artístico-religiosas em contextos de marginalização por meio de uma combinação de recursos metodológicos: etnografia intermitente de longa duração, entrevistas semiestruturadas, observações de campo e interpretações imagéticas. Ao mobilizar todos esses recursos, revela o que ela denomina de base da "cultura pentecostal" na periferia urbana, a qual produz novas sociabilidades a partir da juventude evangélica engajada na arte do grafite. Para Vital da Cunha, a performatividade artística é o recurso estratégico utilizado por jovens evangélicos e marginalizados que acabam se engajando na luta por uma sociedade justa e igualitária.

Voltando para a esfera jurídico-política, Ana Carolina Marsicano e Joanildo Burity, no artigo "Aborto e ativismo 'pró-vida' na política brasileira”, debruçam-se sobre o ativismo "pró-vida" empreendido por grupos religiosos e políticos no Brasil, pinçando cirurgicamente os mecanismos que consolidam a politização religiosa de grupos conservadores antidireitos. De acordo com a autora e o autor, a questão do aborto e as pautas relacionadas a sexualidade e gênero propiciam um cenário fecundo para a defesa parlamentar de pautas moralizantes (e de claro interesse religioso) travestidas de defesa dos valores tradicionais, da família e da 
vida. Especialmente nesses assuntos, a habilidade discursiva desses grupos fica evidente: não se trata de ser contra o aborto, mas a favor da vida. Não se trata de negar direitos à população LGBTQI+, mas de valorizar a importância da família tradicional como célula primeira da sociedade. Ao inverterem os sentidos narrativos, conseguem consolidar uma imagem de defensores de direitos e valores, quando, na prática, procuram sabotar as garantias a direitos fundamentais em uma sociedade pluralista. Há, como consequência dessa atuação, a continuidade lógica em relação a outras pautas como, por exemplo, a formalização do estatuto da família (CARranza; Vital da Cunha, 2018).

Emanuel Freitas da Silva e Emerson Sena, que escrevem "Conflitos entre democracia parlamentar e religião reacionária na Câmara Municipal de Fortaleza”, centram-se num corpus de enunciados políticos para examinar as formas pelas quais os atos linguístico-imagéticos que circulam pelas redes sociais são mobilizados na lógica política, fomentando a negação das diferenças e a imposição da "vontade da maioria" que, no limite, tende a um cenário próximo daquilo que Adam Przeworski (2019) chama de "autoritarismo furtivo". As consequências dessa estratégia, segundo os autores, será a constituição de uma "máquina de guerra reacionária conservadora-cristã", que desgasta os fundamentos da racionalidade institucional do país.

Nota-se, porém, que os fenômenos ocorridos no plano político repercutem também nos debates internos das próprias bases sociais religiosas, gerando uma disputa por hegemonias discursivas. Essa é a discussão trazida por Marcelo Camurça em "Conservadores x progressistas no espiritismo brasileiro: tentativa de interpretação histórico-hermenêutica" Para compreender como se dão essas negociações internas, o autor lança mão de leituras "providencialistas" ou "hermenêuticas" da constituição da identidade espírita. Camurça encontra nesse recurso o amparo para afirmar que a controvérsia e o conflito não são algo conjuntural, mas sim inerentes à própria gênese do espiritismo.

David Oliveira e Erick Cruz de Oliveira, por sua vez, mostram que a questão dos limites do Estado também está em discussão na controvérsia sobre o programa 'Escola Sem Partido', proposta oriunda de alianças entre grupos conservadores que não se limitam a atores religiosos. A partir da análise apresentada no texto "Fundamentalismo religioso: uma chave para entender o programa 'Escola sem Partido"', fica evidente que múltiplas dimensões estão embutidas nas articulações dos atores religiosos no campo legislativo, percebidas a partir dos enunciados discursivos de parlamentares, das formulações de Projetos de Lei de viés reacionário e dos discursos proferidos por parlamentares nas casas legislativas do Brasil. 
O outro lado dessa relação será analisado por Bruno Curtis Weber, por meio da noção de "laicidade às avessas", presente no artigo "Em nome do Laico, do Cisma, da Liberdade Religiosa, amém". O autor sintetiza a percepção que atores religiosos têm sobre o limite do poder público na res religiosa. Para esses atores, o poder público não deve interferir no campo religioso. No entanto, o contrário não apenas é permitido, mas incentivado. Isso pode ser visto, por exemplo, nos Projetos de Lei que preveem a isenção de emolumentos cartoriais e vedação tributária sobre renda e serviços religiosos, por exemplo. Ainda, é com base no mesmo princípio de não interferência que outro Projeto de Lei prevê a exclusão dos crimes de injúria, difamação ou intolerância para ministros de culto. Tudo isso, num paradoxo das consequências, com base em uma legitimação que apela para o Estado laico e para a abstenção da interferência estatal em assuntos religiosos, ao mesmo tempo em que aciona esse mesmo Estado no papel de garantidor de seus privilégios.

Se em um Brasil majoritariamente cristão as relações entre religião e política são quase sempre de cumplicidade para com evangélicos e católicos, pode-se perceber o oposto em relação aos minoritários praticantes das religiões afro-brasileiras. Em "A nova institucionalidade brasileira e os riscos às práticas afrorreligiosas", Valdevino José dos Santos Júnior traz um retrato da sistemática criminalização das atividades litúrgicas dessas religiões no momento de criação das Unidades de Conservação ambientais. Assim, enquanto alguns grupos religiosos vão aperfeiçoando suas estratégias de aproveitamento da institucionalidade política, outros vão sendo ainda mais marginalizados, até mesmo em meio a temas que, à primeira vista, pouco têm a ver com religião. Segundo Santos Júnior, os dispositivos jurídicos utilizados na demarcação de territórios de preservação ambiental acabam interditando o acesso dos afrorreligiosos a esses locais, impedindo a realização de suas liturgias. Conforme mostra o autor, trata-se de mais uma forma de exclusão dessa minoria religiosa, justamente a que mais sofre preconceito e discriminação histórica no Brasil (PRANdi; JÁcomo; BERnARdo, 2019).

As disputas discursivas de ordem religiosa também ultrapassam as fronteiras e são projetadas na política internacional, conforme mostram Jordana de Moraes Neves e Rafael de Oliveira Wachholz em sua análise sobre a atuação da ministra Damares Alves no artigo "A influência da religião na atuação de Damares Alves na Organização das Nações Unidas (ONU)”. O caso conjuntural de Damares explicita o transbordamento, para além das fronteiras brasileiras, de discursos de certos grupos religiosos e reacionários, demonstrando que a ministra interpreta para o Sistema Internacional um Brasil homogeneamente cristão e conservador, jogando para uma suposta organização supranacional esquerdista a responsabi- 
lidade por todas as mazelas que só a restauração moral do país, via religião, seria capaz de dirimir.

Por fim, Fabrício Roberto Costa Oliveira e Cáio César Nogueira Martins, em " $O$ discurso eleitoral da Igreja Universal do Reino de Deus e a ascensão de Bolsonaro”, focam na produção jornalística da Igreja Universal do Reino de Deus, filtrando os textos de cunho político eleitoral nas edições do semanário dessa denominação religiosa. Oliveira e Martins procuram demonstrar os recursos discursivos utilizados pelas lideranças pastorais para se legitimar como "isentas" defensoras da "verdade" - em oposição às supostas fake news propagadas em outros meios. Para os autores, essa foi uma das principais ferramentas utilizadas por essa instituição para influenciar decisões eleitorais dos fiéis. Conforme demonstram em seu artigo, ao longo dos últimos anos os neopentecostais têm penetrado cada vez mais o campo eleitoral, assumindo uma retórica que apela a supostos valores democráticos, formando mais e mais quadros de mobilização coletiva e consolidando sua politização reativa. Vale lembrar, nesse sentido, que tais estratégias costumam ser utilizadas de maneira semelhante também por outras denominações (MARIANO; GERARDI, 2019).

\section{A INDAGAÇÃO QUE PAIRA}

Em suma, são várias as temáticas abordadas nesse dossiê. Alguns textos passam pelo tópico dos direitos reprodutivos e sociais, questões de gênero, tradição religiosa patriarcal e fundamentalismo religioso. Outros tratam da concepção de sociedade que grupos religiosos mantém, as relações que estabelecem com o poder político, a batalha em torno das concepções de laicidade, secularização, liberdade e intolerância religiosa. Ainda, há os que abordam a mídia religiosa, a judicialização da política brasileira e o seu inverso, isto é, a politização do poder judiciário, as intervenções artísticas na cidade, violência urbana e as relações entre religião e meio ambiente.

Frente a esse caleidoscópio, há uma tônica transversal que preocupa, direta ou indiretamente, os autores e as autoras nas suas análises: a escalada dos confrontos que vão das relações macro até as interações microssociais na esfera familiar, o que inclui a radicalização de determinados grupos religiosos, com consequências imprevisíveis e indesejadas para a sociedade brasileira. Paira, então, a pergunta: qual a participação dos grupos, atores, instituições, redes e agências religiosas, quer seja para contribuir no fortalecimento da democracia, quer seja para seu enfraquecimento? 


\section{REFERÊNCIAS}

Almeida, Ronaldo. Bolsonaro presidente: conservadorismo, evangelismo e a crise brasileira. Novos estudos CEBRAP, v. 38, n. 1, p. 185-213, 2019.

. A onda quebrada: evangélicos e conservadorismo. Cadernos Pagu, Campinas, Unicamp, n. 50, 2017.

Alonso, Angela. A política das ruas: protestos em São Paulo de Dilma a Temer. Novos Estudos CEBRAP, São Paulo, n. 37, p. 49-58, 2017.

Carranza, Brenda; Vital da Cunha, Christina. Conservative religious activism in the

Brazilian Congress: Sexual agendas in focus. Social Compass, vol 3. Série 1, p. 287-330, 2018.

Foucault, Michel. A ordem do discurso. São Paulo: Edições Loyola, 2019.

Gabardo, Emerson; Lazzarotto, Gabriel Strapasson; Watzko, Nicholas Andrey Monteiro. Ética pública e parcialidade no combate à corrupção: o caso The Intercept Brasil vs. Operação Lava Jato. International Journal of Digital Law, Belo Horizonte, ano 2, n. 1, p. 151-198, 2021.

Mariano, Ricardo; Gerardi, Dirceu André. Eleições presidenciais na América Latina em 2018 e ativismo político de evangélicos conservadores. Revista USP, n. 120, p. 61-76, 2019.

Pierucci, Antônio Flávio. "Representantes de Deus em Brasília: a bancada evangélica na constituinte”. In: Pierucci, Antônio Flávio; Prandi, Reginaldo (orgs.) A realidade social das religiões no Brasil: religião, sociedade e política. 1.ed. São Paulo: Hucitec, 1996, p. 104-32.

. Eleição 2010: desmoralização eleitoral do moralismo religioso. Novos estudos CEBRAP, n. 89, 2011. DOI: https://doi.org/10.1590/S0101-33002011000100001.

Prandi, Reginaldo; JÁcomo, Luiz; BERnARdo, Terezinha. Trinta anos depois: realidade e pesquisa das religiões afro-brasileiras do centenário da Abolição aos dias de hoje (1988-2018). Revista USP, São Paulo, n. 122, p. 99-120, 2019. DOI: https://doi. org/10.116o6/issn.2316-9036.voi122p99-120.

Prandi, Reginaldo; SANTos, Renan William dos. Quem tem medo da bancada evangélica? Posições sobre moralidade e política no eleitorado brasileiro, no Congresso Nacional e na Frente Parlamentar Evangélica. Tempo Social, vol. 29, n. 2, 187-213, 2017. DOI: https://doi.org/10.11606/0103-2070.ts.2017.110052.

Prandi, Reginaldo; Santos, Renan William dos; Bonato, Massimo. Igrejas evangélicas como máquinas eleitorais no Brasil. Revista USP, (120), 43-60, 2019. DOI: https:// doi.org/10.116o6/issn.2316-9036.voi120p43-6o.

Przeworski, Adam. Crises da democracia. Rio de Janeiro: Zahar, 2019. 
SANTOS, Renan William dos. Entre o "cuidado da casa comum" e a "psicose ambientalista": disputas em torno da ecoteologia católica no Brasil. Revista Brasileira de Sociologia, v. 8, n. 20, p. 78-101, 2020. DOI: http://dx.doi.org/10.20336/rbs.666.

Silva, Marcelo Kunrath; Pereira, Matheus Mazzilli. Movimentos e Contramovimentos Sociais: o caráter relacional da conflitualidade social. Revista Brasileira de Sociologia, v. 8, n. 20, p. 26-49, 2020. DOI: http://dx.doi.org/10.20336/rbs.647.

Teixeira, Ana Claudia; Carranza, Brenda. Ultraconservadores e Campanha da Fraternidade: lógica do confronto. 2021. Disponível em: https://diplomatique.org. br/ultraconservadores-e-campanha-da-fraternidade-logica-do-confronto/. Acesso em 30 de maio de 2021.

VAGGiONE, Juan Marco. "A restauração legal: o neoconservadorismo e o direito na América Latina”. In: VAGgione, Juan Marco; Machado, Maria das Dores Campos; Biroli, Flávia. Gênero, neoconservadorismo e democracia. São Paulo: Boitempo, 2020, 2020, p. 41-82. 